\title{
Blastomycosis in northwestern Ontario, 2004 to 2014
}

\author{
Daniel Dalcin MD(c) $)^{1}$, Syed Zaki Ahmed MD FRCP(C) $)^{1,2}$
}

\begin{abstract}
D Dalcin, Z Ahmed. Blastomycosis in northwestern Ontario, 2004 to 2014. Can J Infect Dis Med Microbiol 2015;26(5):259-262.
\end{abstract}

Blastomycosis is an invasive fungal disease caused by Blastomyces dermatitidis and the recently discovered Blastomyces gilchristii. The medical charts of 64 patients with confirmed cases of blastomycosis in northwestern Ontario during a 10-year period (2004 to 2014) were retrospectively reviewed. The number of patients diagnosed with blastomycosis in Ontario was observed to have increased substantially compared with before 1990, when blastomycosis was removed from the list of reportable diseases. Aboriginals were observed to be disproportionately represented in the patient population. Of the patients whose smoking status was known, $71.4 \%$ had a history of smoking. $59.4 \%$ of patients had underlying comorbidities and a higher comorbidity rate was observed among Aboriginal patients. The case-fatality rate from direct complications of blastomycosis disease was calculated to be $20.3 \%$; this case-fatality rate is the highest ever to be reported in Canada and more than double that of previously published Canadian studies. The clinical characteristics of 64 patients diagnosed with blastomycosis are summarized.

Key Words: Aboriginal; Blastomycosis; Case-fatality; Clinical characteristics; Northwestern Ontario; Smoking

$\mathrm{T}$ he Kenora region of northwestern Ontario has the highest reported incidence of blastomycosis in the world (1). Although several published reports have analyzed the epidemiology of blastomycosis in specific regions and time periods of Ontario, a provincial epidemiological understanding of blastomycosis remains unclear since the removal of blastomycosis from the list of reportable diseases in Ontario in 1990 (2). Despite this caveat, the fragmented epidemiological data available suggest that the number of cases of blastomycosis diagnosed per year in northwestern Ontario is increasing $(3,4)$.

Thunder Bay, Ontario is the largest city in northwestern Ontario and provides health services to a large surrounding rural catchment area that contains a substantial Aboriginal population. The Thunder Bay Regional Health Sciences Centre (TBRHSC) is the only academic hospital in northwestern Ontario and is the treatment centre for patients requiring specialized, acute or complex care, in addition to standard local medical services. The objective of the present study was to analyze blastomycosis disease in patients presenting at the TBRHSC.

\section{METHODS}

The medical files of 64 patients with confirmed cases of blastomycosis that presented at the TBRHSC from February 1, 2004 to January 31, 2014, were retrospectively reviewed. Similar to Crampton et al (4), confirmed cases of blastomycosis were defined as patients with a clinically compatible illness that was corroborated by a clinical specimen that grew Blastomyces species yeast cells in culture or microscopically visualized by a pathologist. The racial status of patients was defined as either Aboriginal or non-Aboriginal. To determine whether the Aboriginal patients in the present study had a statistically significant

\section{La blastomycose au nord-ouest de l'Ontario de 2004 à 2014}

La blastomycose est une maladie fongique invasive causée par la Blastomyces dermatitidis et le Blastomyces gilchristii, récemment découvert. Les chercheurs ont réalisé une analyse rétrospective des dossiers médicaux des 64 patients atteints d'une blastomycose confirmée au nord-ouest de l'Ontario, déclarés sur une période de dix ans (2004 à 2014). Le nombre de patients ayant un diagnostic de blastomycose en Ontario avait considérablement augmenté par rapport à celui d'avant 1990, lorsque la blastomycose a été retirée de la liste de médicaments à déclaration obligatoire. Le nombre d'Autochtones représenté au sein de la population de patients était disproportionné. Chez les patients dont on connaissait le statut de fumeur, 71,4 \% avaient des antécédents de tabagisme, 59,4\% présentaient des comorbidités sousjacentes, et le taux de comorbidités était plus élevé chez les patients autochtones. Le taux de mortalité causé par les complications directes de la blastomycose s'élevait à 20,3\%. C'est le taux le plus élevé jamais déclaré au Canada, soit plus de deux fois celui signalé auparavant dans les études canadiennes. Les caractéristiques cliniques des 64 patients atteints d'une blastomycose diagnostiquée sont résumées. increased proportion of comorbidities compared with non-Aboriginal patients, a contingency table was used to test for significance using the $\chi^{2}$ distribution; statistical significance was determined to be $\mathrm{P}<0.05$. The Northwest Community Health Integration Network Population Health Profile was used to obtain demographic data on the catchment population of the TBRHSC (5). The present study was approved by the research ethics boards of all involved institutions.

\section{Age and sex}

\section{RESULTS}

Of the patients with blastomycosis, $65.6 \%$ were male. The mean age of patients diagnosed with blastomycosis was 41.2 years (range 12 to 82 years). Patients 20 to 59 years of age accounted for $75 \%$ of the patient total (Table 1).

\begin{abstract}
Timing of clinical presentation
Due to incomplete information from patients transferred to the TBRHSC from other facilities, the month and year of diagnosis was available for only 60 patients. Cases of blastomycosis were diagnosed in all months of the year; however, a slightly higher proportion of patients were diagnosed between October and March $(60.0 \%$ of patients). The number of cases diagnosed per year ranged from two to 11 cases, with a mean of 6.4 cases per year (Figure 1 ).
\end{abstract}

\section{Comorbidities}

Comorbidities were present in $59.4 \%$ of patients; $73.3 \%$ of Aboriginal patients were comorbid, compared with $48.5 \%$ of the non-Aboriginal patients, and the difference was statistically significant (Tables 2 and 3 ).

${ }^{1}$ Northern Ontario School of Medicine; ${ }^{2}$ Department of Internal Medicine, Thunder Bay Regional Health Sciences Centre, Thunder Bay, Ontario Correspondence: Daniel Dalcin, Northern Ontario School of Medicine, 955 Oliver Road, Thunder Bay, Ontario P7B 5E1.

e-mail ddalcin@nosm.ca 
TABLE 1

Age, sex, Aboriginal heritage and case-fatality rate among 64 patients with blastomycosis

\begin{tabular}{|c|c|c|c|c|c|c|}
\hline \multirow[b]{2}{*}{ Age, years } & \multirow[b]{2}{*}{ Age group total } & \multicolumn{3}{|c|}{ Patients } & \multirow[b]{2}{*}{ Death count, $n$} & \multirow[b]{2}{*}{ Case fatality, \% } \\
\hline & & Male & Female & Aboriginal & & \\
\hline $20-29$ & $17(26.6)$ & $9(52.9)$ & $8(47.1)$ & $11(64.7)$ & 3 & 17.6 \\
\hline $40-49$ & $11(17.2)$ & $8(72.7)$ & $3(27.3)$ & $5(45.4)$ & 2 & 18.2 \\
\hline 50-59 & 7 (10.9) & $3(42.9)$ & $4(57.1)$ & $3(42.9)$ & 3 & 42.9 \\
\hline $60-69$ & $5(7.8)$ & $4(80.0)$ & $1(20.0)$ & $2(40.0)$ & 1 & 20.0 \\
\hline$>79$ & $1(1.6)$ & $1(100.0)$ & $0(0.0)$ & $0(0.0)$ & 0 & 0.0 \\
\hline Total, $\mathrm{n}$ & 64 & 41 & 23 & 32 & 13 & 20.3 \\
\hline
\end{tabular}

Data presented as $n$ (\% of age group) unless otherwise indicated

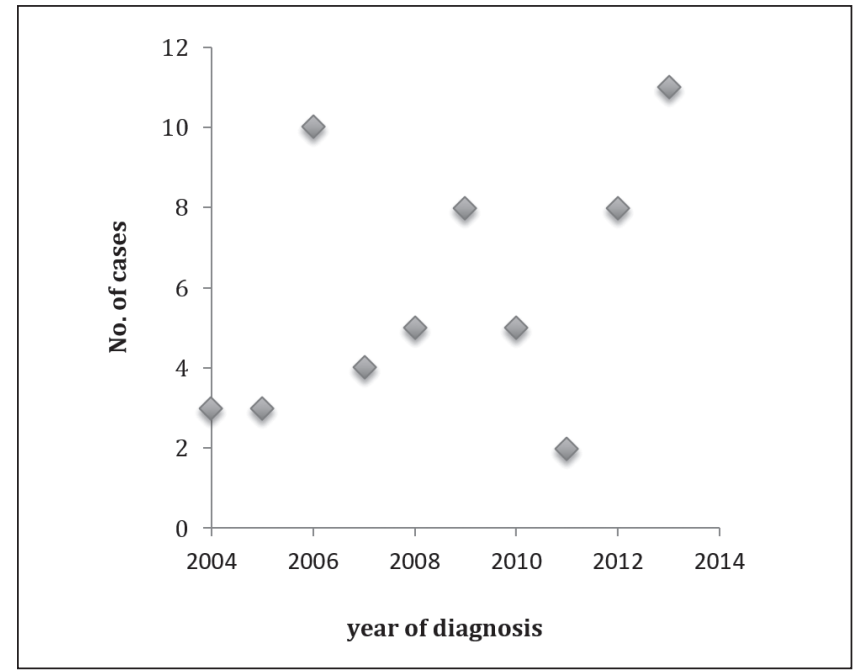

Figure 1) Number (No) of patients presenting with blastomycosis at the Thunder Bay Regional Health Services Centre (TBRHSC, Thunder Bay, Ontario) according to year of diagnosis from February 1, 2004 to January 31, 2014. The number of cases of blastomycosis diagnosed in Ontario has substantially increased since 1990, when a mean of two cases were diagnosed per year. The mean number of cases diagnosed at the TBRHSC was 6.4 per year

\section{Aboriginal heritage}

Race was specified in 63 (98.4\%) of patient medical records. Of the 63 patient medical records that specified Aboriginal status, 30 (47.6\%) patients were of Aboriginal heritage.

\section{System involvement}

Fifty-five patients $(85.9 \%)$ had only pulmonary involvement, six patients $(9.4 \%)$ had central nervous system involvement (three of the six patients with central nervous system involvement also had pulmonary involvement), four patients $(6.3 \%)$ had skin involvement and one patient $(1.6 \%)$ had synovial fluid involvement. Two of the 11 patients $(18.2 \%)$ with extrapulmonary involvement (skin and synovial fluid) were pregnant women.

\section{Smoking status}

Smoking status was available for 53 of the 64 patients in the present study. Of these 53 patients, $71.4 \%$ had a history of smoking.

\section{Patients who died}

Intenstive care unit (ICU) care was required for 36 patients. Of these 36 patients, $13(36.1 \%)$ patients died of direct complications of blastomycosis; there were no deaths from patients that did not require ICU care. The overall case-fatality rate observed was $20.3 \%$; this may be the highest case-fatality rate of blastomycosis to be described in Canada.
TABLE 2

Comorbidities of patients diagnosed with blastomycosis according to Aboriginal status

\begin{tabular}{lccc}
\hline Comorbidity & Patients, $\mathbf{n}$ & $\begin{array}{c}\text { Aboriginal, } \\
\mathbf{n}(\%)\end{array}$ & $\begin{array}{c}\text { Non-Aboriginal, } \\
\mathbf{n}(\%)\end{array}$ \\
\hline T1DM & 3 & $2(66.7)$ & $1(33.3)$ \\
T2DM & 14 & $11(78.6)$ & $3(21.4)$ \\
Liver failure & 1 & $0(0)$ & $1(100)$ \\
COPD & 4 & $0(0)$ & $4(100)$ \\
Renal failure & 5 & $5(100)$ & $0(0)$ \\
Previous MI & 3 & $1(33)$ & $2(66.7)$ \\
Tuberculosis & 2 & $1(50)$ & $1(50)$ \\
Colon cancer & 2 & $0(0)$ & $2(100)$ \\
Cerebral palsy & 2 & $1(50)$ & $1(50)$ \\
T2DM and COPD & 2 & $1(50)$ & $1(50)$ \\
Total & $38(100)$ & $22(57.9)$ & $16(42.1)$ \\
\hline
\end{tabular}

COPD Chronic obstructive pulmonary disease; MI Myocardial infarction; T1DM Type 1 diabetes mellitus; T2DM Type 2 diabetes mellitus

All patients had a diagnosis of blastomycosis established at the time of death. The age of patients that died ranged from 26 to 73 years (Figure 2). Eleven $(84.5 \%)$ of the patients that died were between 26 to 55 years of age. Nine $(67 \%)$ of the patients that died were male.

Smoking status was documented for nine of the 13 patients that died. Eight of the patients that died smoked or had a history of smoking, and one patient identified as a nonsmoker.

Except for one patient, all patients who died had health problems before aquiring blastomycosis. These underlying health problems included: liver failure $(\mathrm{n}=1)$, chronic obstructive pulmonary disease $(n=2)$, tuberculosis $(n=2)$, type 1 diabetes mellitus $(n=2)$, type 2 diabetes mellitus $(n=1)$, drug/alcohol abuse $(n=1)$, renal failure $(n=1)$, colorectal cancer $(n=1)$, and both chronic obstructive pulmonary disease and type 2 diabetes mellitus $(n=1)$.

\section{DISCUSSION}

Seasonal variation in clinical presentation

Consistent with other reports $(1,3,6), 60 \%$ of patients were diagnosed between October and March. It has been suggested that the increase in patients diagnosed during the fall and winter months is due to acquisition of Blastomyces species conidia during the summer months, followed by a one to six month presymptomatic incubation period (6).

Sex

Similar to the results of other studies $(1,4), 65.6 \%$ of patients with blastomycosis were male. It is believed that the increase in males affected by blastomycosis is a function of increased environmental exposure (7).

Increased number of cases diagnosed per year post-1990 Based on published epidemiological reports, the number of cases of blastomycosis diagnosed per year in Ontario has increased substantially 
TABLE 3

Comparison of comorbid status between Aboriginal and non-Aboriginal patients diagnosed with blastomycosis

\begin{tabular}{lccc}
\hline Status & Aboriginal & Non-Aboriginal & Total \\
\hline Comorbid & 22 & 16 & 38 \\
Non-comorbid & 8 & 17 & 25 \\
Total & 30 & 33 & 63 \\
\hline
\end{tabular}

Data presented as $n$. Of the 64 patients in the present study, race was specified in 63 patients. Of the Aboriginal patients, $73.3 \%$ were comorbid, compared with $48.5 \%$ of the non-Aboriginal patients, and the difference was statistically significant (Pearson's $\chi^{2}=4.054, d f=1, P=0.044$ )

since $1990(3,8)$. Leading up to the removal of blastomycosis from the list of reportable diseases in Ontario in 1990, there were only 16 cases of blastomycosis reported in Ontario between 1981 and 1989 (mean of two cases per year) $(2,3)$.

Sixty-four cases of blastomycosis were diagnosed at the TBRHSC during the 10-year period between 2004 and 2014 (mean of 6.4 cases per year), which far exceeds the number of cases diagnosed per year before 1990. This increase in blastomycosis diagnosis is not proportional to the population growth of Ontario. Ontario's population has grown approximately $37 \%$ from 1990 to 2014, from an estimated 10 million in 1990 to 13.7 million in 2014 (9). Moreover, the present study only involved patients with blastomycosis presenting to the TBRHSC, suggesting that the actual mean of blastomycosis diagnoses in Ontario is $>6.4$ cases per year. An epidemiological analysis of blastomycosis in Ontario (1994 to 2003) found 309 cases of blastomycosis were reported in Ontario over a 10-year period (mean of 30.9 cases per year) (3). The same study noted that the number of blastomycosis cases reported per year demonstrated a trend of increasing annual incidence (3).

While Ontario removed blastomycosis from the list of reportable diseases in 1990, Illinois (USA) instated blastomycosis as a mandatory reportable disease in 1994 due to an increased number of diagnosed cases (8). Our results indicate that the number of cases of blastomycosis diagnosed per year has increased substantially since 1990, from a mean of two cases per year in Ontario to a mean of 6.4 cases per year in northwestern Ontario (Figure 1) $(3,8)$.

The reasons for the increase in blastomycosis diagnoses are unclear and require further study. Some possible factors contributing to the increase in blastomycosis diagnoses include increased awareness by clinicians, which may have resulted in a substantial increase in testing rates, or expanding ecological niche of Blastomyces. Looking to the future, climate change is projected to create favourable ecological conditions for Blastomyces species. The projected drier summers and increased winter precipitation associated with climate change in North America is expected to create optimal conditions for Blastomyces species spore dispersal, suggesting that blastomycosis infection may become more prevalent than currently observed (10).

It is clear that the number of blastomycosis diagnoses per year in Ontario has increased considerably compared with the number of cases diagnosed per year before 1990. Given this increase, the possible increase in Blastomyces species prevalence associated with climate change, and a significantly high case-fatality rate, it is reasonable to consider reinstating blastomycosis to the list of reportable diseases in Ontario. We, along with other authors, advocate for the reinstatement of blastomycosis to the list of reportable diseases in Ontario (3).

\section{High case fatality}

In the present study, $20.3 \%$ of patients died from direct complications of blastomycosis, which far exceed the case-fatality rate of the two other Canadian studies that had case-fatality rates of $6.3 \%$ and $8 \%$, respectively $(4,11)$. There are several reasons that may account for the high case-fatality rate observed including our patient population and the virulence of $B$ gilchristii and $B$ dermatitidis.

Because our study evaluated patients at the TBRHSC (a 395-bed hospital) and the other two Canadian studies evaluated patients diagnosed with blastomycosis in hospitals with $>150$ to 200 beds, our patient

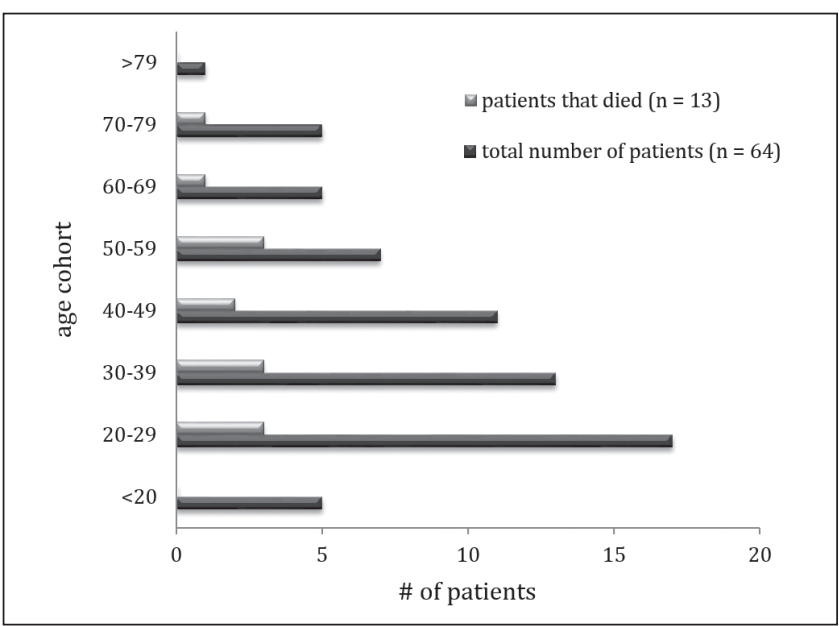

Figure 2) Age distribution of all patients diagnosed with blastomycosis versus patients diagnosed with blastomycosis who died. Most of the 13 patients who died directly from blastomycosis-related complications at the Thunder Bay Regional Health Services Centre (Thunder Bay, Ontario) were middle-aged. There were no deaths of patients $<20$ or $>79$ years of age

population is selected to be more critically ill and/or comorbid, which would contribute to the higher case-fatality rate observed $(4,11)$. For example, $56.3 \%$ of our patients required care in the ICU, compared with the study conducted by Kralt et al (11) where only $10 \%$ of patients required ICU care. Although the study conducted by Crampton et al (4) does not discuss what proportion of patients required ICU care, it is clear that our patient population was more seriously ill; $100 \%$ of our patients were symptomatic whereas only $91.9 \%$ of their patient population was symptomatic. Although the case-fatality rates of these two other studies were also subject to elevation from the underdiagnosis of mild subclinical cases because their analysis only focused on hospitals with $>150$ to 200 beds, it is clear that our high-case fatality rate is a function of our critically ill patient population.

An additional factor that may have contributed to the high casefatality rate observed is differences in ecology and virulence among $B$ dermatitidis and B gilchristii (12). Brown et al (12) analyzed the geographical distribution of $B$ dermatitidis versus $B$ gilchristii and found that $B$ gilchristii clinical isolates were predominantly located in areas where blastomycosis is hyperendemic, such as northwestern Ontario, whereas $B$ dermatitidis clinical isolates were broadly distributed across North America. This difference in ecological distribution may be substantiated by differences in virulence between these two fungal species. A preliminary study that compared isolates of $B$ gilchristii and $B$ dermatitidis found $B$ gilchristii to be highly virulent, causing an infection and immunocompetent mice and humans, whereas B dermatitidis was described as less virulent and unable to cause illness or death in mice (12). These findings, in the context of our results, provide a framework for further research. Additional analysis is required to determine whether the increased frequency in diagnosis of blastomycosis and associated high case-fatality rate in northwestern Ontario is attributable to the emergence as B gilchristii as a more virulent species (12).

\section{Smoking}

Of the patients whose smoking status was documented, $71.4 \%$ had a history of smoking. Given that $23.2 \%$ of the population of Thunder Bay are current or previous smokers and $23.9 \%$ of the population of the northwest Local Health Integration Network has a history of smoking, this clearly indicates that smokers are disproportionately affected by blastomycosis $(5,13)$.

The typical course of blastomycosis infection begins with the inhalation of airborne Blastomyces species conidia. Under normal physiological conditions, these inhaled conidia are rapidly phagocytized by alveolar macrophages, neutrophils or monocytes (14). However, if phagocytosis is incomplete, the remaining conidia have the potential to 
transform into a pathogenic yeast form within $24 \mathrm{~h}$ to $72 \mathrm{~h}$ of inhalation via a temperature-dependent morphological transition. This yeast form of Blastomyces species permits infection to persist because the yeast cell is too large to be phagocytized by polymorphonuclear cells (15). Smoking may increase the risk of contracting blastomycosis through several mechanisms that damage the immunocompetency of the respiratory tree, including impaired mucociliary clearance and reduced phagocytic ability of alveolar macrophages (16-20).

\section{Aboriginal status}

Because Aboriginals account for only $19.2 \%$ of the population of the northwestern Ontario and $47.6 \%$ of patients with blastomycosis were identified as Aboriginal, our results indicate that Aboriginals are disproportionately affected by blastomycosis (Table 1) (5). One factor that likely contributed to this observed disparity is comorbidity status. We found that the Aboriginal patients diagnosed with blastomycosis were statistically more likely to be comorbid compared with the non-Aboriginal patients who were diagnosed with blastomycosis (Tables 2 and 3).

In Canada, the smoking rate among Aboriginals is approximately twice as high than that of non-Aboriginals (20). Given this risk factor, it is not surprising that Canadian Aboriginals are disproportionately affected by respiratory disease (21). Although our study did not have statistical power to evaluate this possibility, it is likely that the higher smoking rate among Aboriginals contributed to this disparity.

\section{Limitations}

Our study had a small sample size $(n=64)$. Due to the infrequency of disease, it is challenging to obtain a large sample size sufficient to conduct a more robust analysis.

\section{REFERENCES}

1. Dwight P, Naus M, Sarsfield P, Limerick B. An outbreak of human blastomycosis: The epidemiology of blastomycosis in the Kenora catchment region of Ontario, Canada. Can Commun Dis Rep 2000;26:82-91.

2. Population and Public Health Branch: Summary of Reportable Diseases 1990. Toronto: Communicable Diseases Control, Ontario Ministry of Health; 1991.

3. Morris S, Brophy J, Richardson S, et al. Blastomycosis in Ontario, 1994-2003. Emerg Infect Dis 2006;12:275-9.

4. Crampton T, Light R, Berg G, et al. Epidemiology and clinical spectrum of blastomycosis diagnosed at Manitoba hospitals. Clin Infect Dis 2002;34:1310-6.

5. Northwest Community Health Integration Network Population Health Profile. <www.northwestlhin.on.ca/resources/ /media/sites/ nw/uploadedfiles/Home_Page/Report_and_Publications/ Population\%20Report\%202013\%20English.pdf> (Accessed August 12, 2014).

6. Light B, Kralt D, Embil J, et al. Seasonal variations in the clinical presentation of pulmonary and extrapulmonary blastomycosis. Med Mycol 2008;46:835-41.

7. Saccente M, Woods G. Clinical and laboratory update on blastomycosis. Clin Microbiol Rev 2010;23:367-81.

8. Dworkin M, Duckro, Proia N, Semel J, Huhn G. The epidemiology of blastomycosis in Illinois and factors associated with death. Clin Infect Dis 2005;41:107-11.

9. Statistics Canada. Population by year, by province and territory (Number). <www.statcan.gc.ca/tables-tableaux/sum-som/101/cst01/ demo02a-eng.htm> (Accessed on September 15, 2014).

10. Greer A, Ng V, Fisman D. Climate change and infectious diseases in North America: the road ahead. CMAJ 2008;178:715-22.

11. Kralt D, Light B, Cheang M, et al. Clinical characteristics and outcomes in patients with pulmonary blastomycosis. Mycopathologia 2009;167:115-24.

12. Brown E, McTaggart L, Zhang S, et al. Phylogenetic analysis reveals a cryptic species of Blastomyces gilchristii, sp. nov. within the human pathogenic fungus Blastomyces dermatitidis. PLoS ONE 8:1-13.
The referral pattern of patients diagnosed with blastomycosis in the Kenora region of northwestern Ontario adds an element of complexity to interpreting our results. Depending on weather, health care resources and patient conditions, patients with blastomycosis in the Kenora area may be transferred to the TBRHSC in Ontario or a hospital in Manitoba.

Our study only examined patients diagnosed, referred or transferred to the TBRHSC. Therefore, mild or subclinical cases of blastomycosis in northwestern Ontario were excluded from the present analysis.

\section{CONCLUSION}

Blastomycosis has a wide spectrum of clinical presentation, ranging from subclinical infection to acute respiratory distress syndrome. Nonspecific symptoms, a long incubation period, the lack of a detectable biomarker with high specificity and infrequency of disease contribute to the high rates of late or missed diagnoses (22). Awareness of blastomycosis by clinicians practicing in endemic areas has the potential to reduce the high rate of morbidity and mortality associated with this fungal disease. The present study was the first to evaluate the breadth of blastomycosis disease in the Thunder Bay District of northwestern Ontario. To that end, our results provide valuable clinical information, a framework for further research, and a basis for re-examining the validity of the removal of blastomycosis from the list of reportable diseases in Ontario.

ACKNOWLEDGEMENTS: Daniel Dalcin was funded by a Dean's Medical Student Research Award from the Northern Ontario School of Medicine. The authors are grateful for helpful advice from Dr Eli Nix and Bruce Weaver.
13. Statistics Canada 2013 Community Profiles-Health Region. Updated 2008. <www12.statcan.ca/english/census06> (Accessed September 9, 2014).

14. Drutz D, Frey C. Intracellular and extracellular defenses of human phagocytes against Blastomyces dermatitidis and yeasts. J Lab Clin Med 1985;105:737-50.

15. Klein B. Immunology of blastomycosis. In: Greenough III, ed. Current Topics in Infectious Diseases. New York: Plenum Publishing Corporation, 1992;133-63.

16. Wanner A, Slathe M, O'Riordan T. Mucociliary clearance in the airways. Am J Resp Crit Care Med 1996;154:1868-1902.

17. Hodge S, Hodge G, Ahern J, Jersmann H, Holmes M, Reynolds P. Smoking alters alveolar macrophage recognition and phagocytic ability: Implications in chronic obstructive pulmonary disease. Am J Respir Mol Biol 2007;37:748-55.

18. Green G, Carolin D. The depressant effect of cigarette smoke on the in vitro antibacterial activity of alveolar macrophages. N Engl J Med 1967;276:421-7.

19. Sethi S, Murphy T. Infection in the pathogenesis and course of chronic obstructive pulmonary disease. N Engl J Med 2008;359:2355-65.

20. Physicians for a Smoke-Free Canada (2013). Factsheets: Smoking among Aboriginal Canadians. <www.smoke-free.ca/factsheets/pdf/ cchs/Aboriginal.pdf> (Accessed April 24, 2015).

21. Ospina M, Voaklander D, Senthilselvan A, et al. Incidence and prevalence of chronic obstructive disease among Aboriginal peoples in Alberta, Canada. PLoS One 2015;10:1-13.

22. Chapman W, Dismukes W, Proia, L, et al. Clinical practice guidelines for the management of blastomycosis: 2008 update by the Infectious Diseases Society of America. Clin Infect Dis 2008;46:1801-12. 


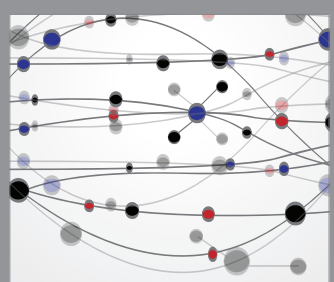

The Scientific World Journal
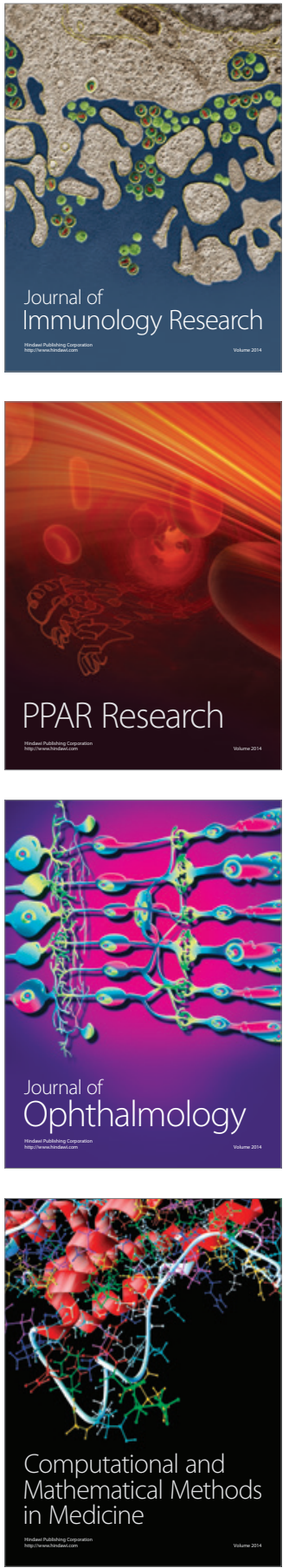

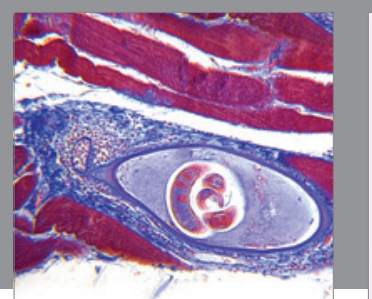

Gastroenterology Research and Practice

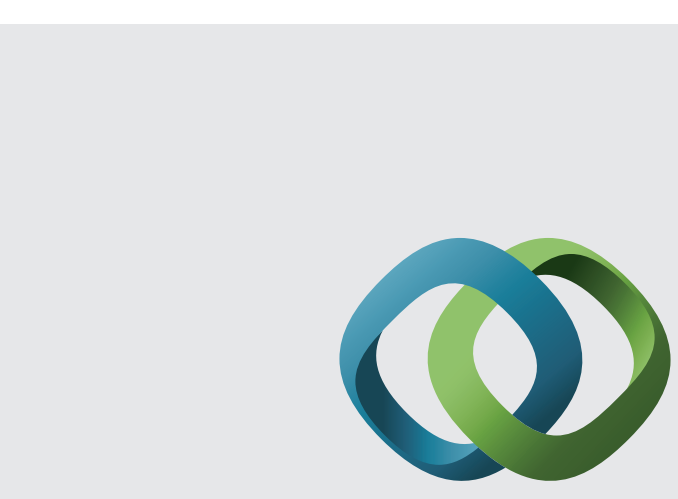

\section{Hindawi}

Submit your manuscripts at

http://www.hindawi.com
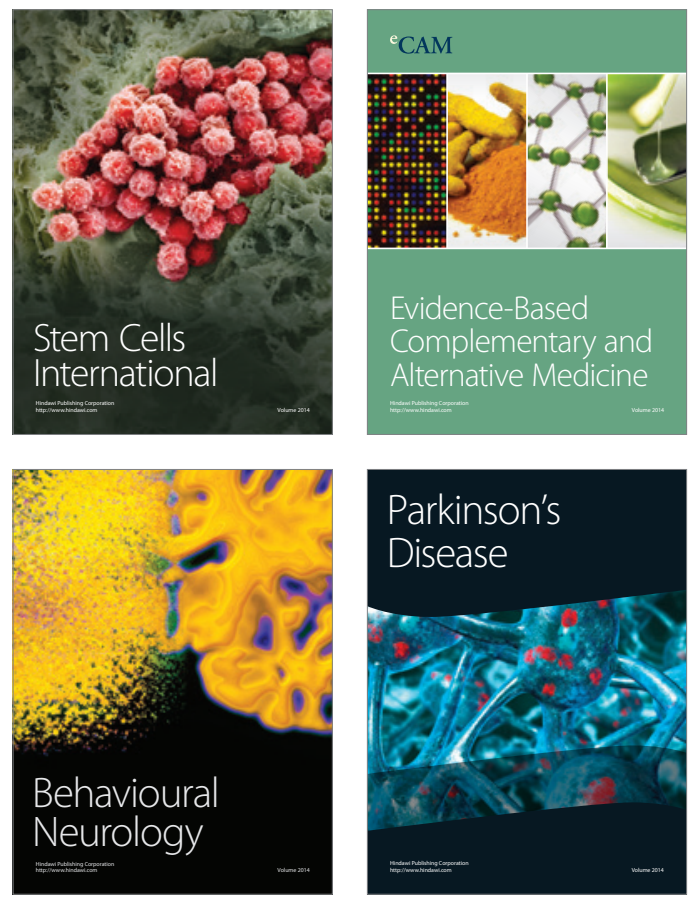
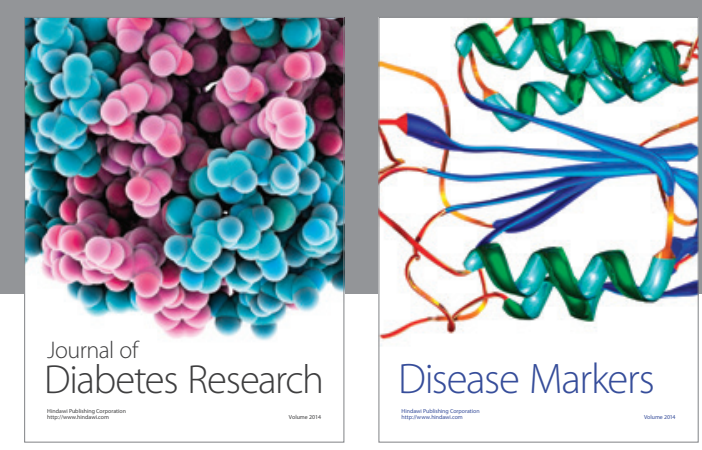

Disease Markers
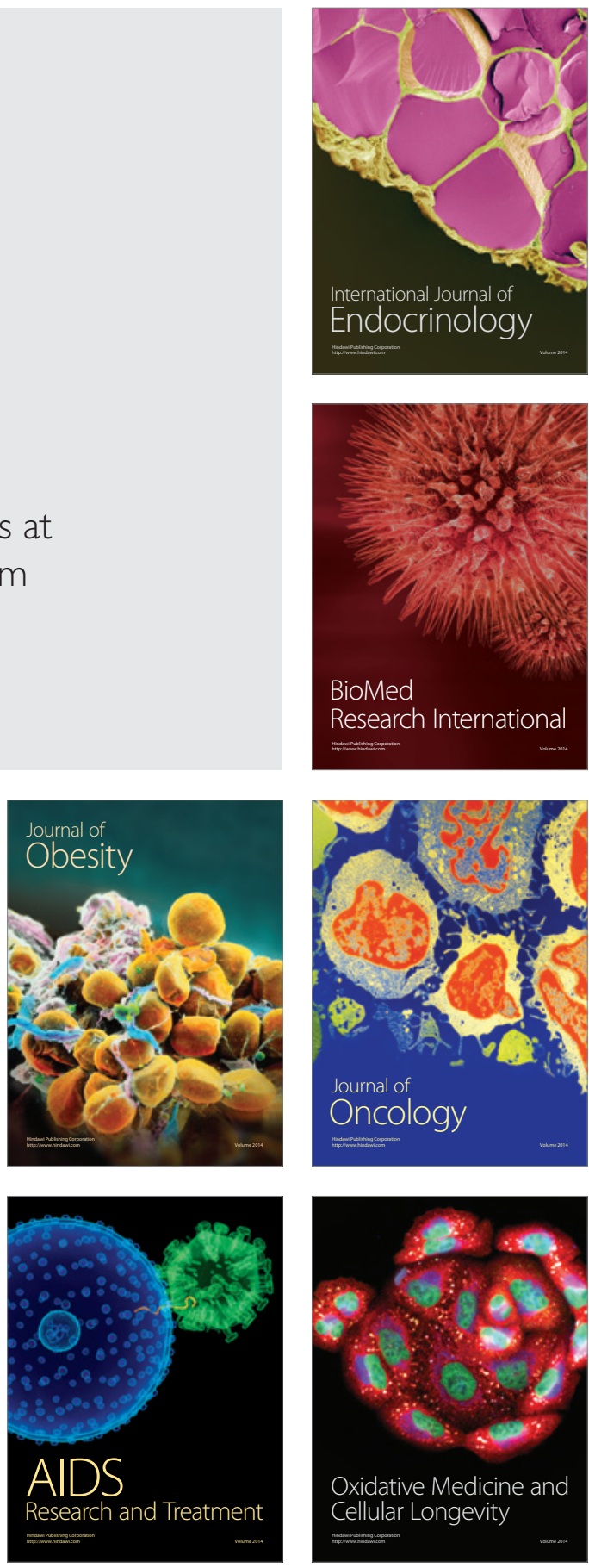